\title{
O LUGAR DAS CRIANÇAS COM DEFICIÊNCIAS NA EDUCAÇÃO INFANTIL E POLÍTICAS DE INCLUSÃO NA EDUCAÇÃO BRASILEIRA
}

\author{
EL LUGAR DE LOS NIÑOS CON DISCAPACIDADES EN LAS POLÍTICAS DE \\ EDUCACIÓN E INCLUSIÓN EN LA PRIMERA INFANCIA EN LA EDUCACIÓN \\ BRASILEN A
}

\author{
THE PLACE OF CHILDREN WITH SPECIAL NEEDS IN CHILD EDUCATION AND \\ INCLUSION POLICES IN BRAZILIAN EDUCATION
}

\author{
Solange Aparecida de Souza MONTEIRO ${ }^{1}$ \\ Paulo Rennes Marçal RIBEIRO ${ }^{2}$
}

\begin{abstract}
RESUMO: Nesse artigo buscamos refletir sobre qual "o lugar" que as crianças pequenas com deficiência, da Educação Infantil, de zero a cinco anos de idade, ocupam nas ações e políticas promovidas pelo Estado na educação brasileira, frente à necessidade em tomar conhecimento de quem são nos sistemas de ensino, quais as suas demandas diante da educação e se elas possuem algum espaço nas instituições de Educação Infantil. Subsidiados pela literatura científica e legislação nacional, concluímos que o lugar atribuído às crianças com deficiência, nas pesquisas, pelo poder público e pela sociedade de modo geral, é ainda o da invisibilidade, quando consideramos a inclusão dos alunos público-alvo da Educação Especial na Educação Infantil. Essas crianças, ao longo de toda história, foram direcionadas a ocupar um "nãolugar", um espaço onde os direitos sociais e a cidadania lhes são negados. Com essa reflexão, buscou-se dar ressignificação à essa invisibilidade tanto na legislação, quanto nos contextos das pesquisas em educação e, especificamente, da Educação Infantil.
\end{abstract}

PALAVRAS-CHAVE: Educação infantil. Deficiência. Inclusão.

RESUMEN: En este artículo tratamos de reflexionar sobre lo que "el lugar" que los niños pequeños con discapacidades, de cero a cinco años de edad, ocupan en las acciones y políticas promovidas por el estado en la educación brasileña, ante la necesidad de tomar conocimiento Quiénes son en los sistemas educativos, cuáles son sus exigencias frente a la educación y si tienen algún espacio en las instituciones educativas de la primera infancia. Subvencionado por la literatura científica y la legislación nacional, concluimos que el lugar atribuido a los niños con discapacidades, en la investigación, por las autoridades públicas y por la sociedad en general, sigue siendo la invisibilidad, cuando consideramos la inclusión de los estudiantes El público objetivo de la educación especial en la educación de la primera infancia. Estos niños, a lo largo de la historia, fueron dirigidos a ocupar un "no-lugar", un

\footnotetext{
${ }^{1}$ Instituto Federal de Educação Ciência e Tecnologia de São Paulo (IFSP), Araraquara - SP - Brasil. Mestra em Processos de Ensino, Aprendizagem e Inovação. ORCID: 〈http://orcid.org/0000-0002-1640-0266>. E-mail: solmonteiro@ifsp.edu.br

${ }^{2}$ Universidade Estadual Paulista (UNESP), Araraquara - SP- Brasil. Docente do Programa de Pós-Graduação em Educação Sexual, e no PPG Educação Escolar. ORCID: <https://orcid.org/0000-0002-1552-5702>. E-mail: paulo.rennes@unesp.br
} 
espacio donde los derechos sociales y la ciudadanía les son negados. Con esta reflexión, buscamos dar resignificación a esta invisibilidad tanto en la legislación como en los contextos de investigación en educación y, concretamente, en la educación de la primera infancia.

PALABRAS CLAVE: Educación de la primera infancia. Discapacidad. Inserción.

ABSTRACT: In this article we try to think about which is "the place" where little children with special needs, in Child Education, from zero to five years old, have in actions and polices promoted by the Government in Brazilian education, hence the need to acknowledge who are they on the education system, which are their demands and if they do have any room in child education institutions. Based on the scientific literature and national legislation, we arrived at the conclusion that the place given to children with special needs, in research, by the public power and society in general, is still of invisibility, when we consider the inclusion of Special Education target audience students in Child Education. These children, through the history, were directed to occupy a "non-place", were both social rights and citizenship are denied to them. With this reflection, we tried to do a resignification to this invisibility as much in the legislation, as in the education research fields and, specifically, of child education.

KEYWORDS: Child education. Special needs. Inclusion.

\section{Introdução}

"Um dia me disseram que as nuvens não eram de algodão" Engenheiros do Hawaii

A inclusão implica mudanças de paradigma, conceitos e posições que escapam às regras educacionais tradicionais. Na Educação Infantil, a perspectiva inclusiva revolucionou o sistema organizacional e as propostas curriculares atuais. A meta da inclusão escolar no ensino infantil é transformar instituições, de modo que se tornem espaços de formação e de ensino de qualidade para todas as crianças, mesmo aquelas que apresentam necessidades próprias e diferentes das demais crianças no domínio das aprendizagens correspondentes a sua idade e requerem recursos pedagógicos e metodologias educacionais específicas.

Nesse sentido, são objetivos principais da Educação Especial proporcionar ao seu público-alvo: alunos com deficiências, com transtorno global do desenvolvimento e altas habilidades/superdotação, matriculado na Educação Infantil, a promoção de suas capacidades, envolvendo o desenvolvimento pleno de sua personalidade, a participação ativa na vida social e no mundo do trabalho, assim como o desenvolvimento biopsicossocial, proporcionando 
maior autonomia às crianças de 0 a 5 anos. Assim como a formação docente para atuação com o público-alvo da Educação Especial na Educação Infantil também requer investimentos, quer seja no âmbito das políticas públicas e sua operacionalização, quer seja na reorganização das escolas para acomodar práticas pedagógicas alinhadas à perspectiva da educação inclusiva

Para os professores que trabalham com educação inclusiva, são necessárias mudanças estruturais e educacionais, para desobstruir barreiras e abrir portas e janelas para alunos com deficiências, com enfoque principalmente em suas habilidades, o que não significa deixar de considerar as implicações derivadas das características de cada aluno. Significa compreender essas características como inerentes à heterogeneidade do público-escolar e, particularmente, do público-alvo da Educação Especial. Na formação inicial e continuada do professor são necessários, portanto, investimentos que também contemplem a ação pedagógica focada no contexto da Educação Infantil.

O direito à igualdade e equidade configura-se como uma oportunidade para todos no oferecimento a cada sujeito do que melhor se ajuste às suas demandas educacionais, o que inclui seus interesses e habilidades, bem como pressupõe a produção de conhecimentos que respeitem essa heterogeneidade na busca pela garantia de educação de qualidade.

Ao abordar o ambiente da Educação Infantil e as pessoas com deficiência, neste artigo buscamos refletir sobre qual "o lugar" que as crianças pequenas com deficiência, , de zero a cinco anos de idade, ocupam nas ações e políticas promovidas pelo Estado na educação brasileira, frente à necessidade em tomar conhecimento de quem são nos sistemas de ensino, quais as suas demandas diante da educação e se elas possuem algum espaço nas instituições de Educação Infantil. Para tal, parte-se de uma reflexão acerca da relação entre Educação Especial e educação inclusiva e as implicações na invisibilidade conferida às crianças com deficiências na Educação Infantil, bem como consideramos as implicações da Base Nacional Comum Curricular (BNCC) (BRASIL, 2017) e da formação docente para a inclusão desse público na Educação Infantil.

\section{Educação especial e educação inclusiva: implicações na invisibilidade de crianças com deficiências na Educação Infantil}

"Todo mundo tem seu jeito singular de crescer, aparecer e se manifestar"
Lenine

Para Sassaki (2007) inclusão "[...] é um processo de mudança do sistema social comum, para acolher toda a diversidade humana. Para a maioria das pessoas, quando se fala 
em inclusão, muitas vezes pensa-se no aspecto de uma pessoa que estava excluída para ser "colocada dentro", para não ser marginalizada, discriminada".

A inclusão privilegia a valorização da dimensão humana, a criança com seus direitos fundamentais garantidos desde os primeiros anos de vida. $\mathrm{O}$ paradigma anterior propunha um assistente para a educação compensatória, talvez tenha surgido para o pensamento em vista da visão integral do desenvolvimento em que ele se tornara uma pessoa autônoma e inserida num determinado contexto sócio-histórico-cultural.

Nesse sentido, Carneiro (2016) alega que as escolas de Educação Infantil não estão preparadas para o atual contexto educacional e que '[...] possibilidade de reflexão para estudiosos da Educação que se preocupam com a qualidade do serviço oferecido pela escola, especialmente em momento de mudança de paradigma como o que estamos atravessando [...]". (CARNEIRO, 2016, p. 860).

A trajetória dos alunos público-alvo da Educação Especial tem sido marcada por eventos históricos, incluindo sofrimento, exclusão social, preconceito, abandono e até a eliminação da pessoa doente. A pessoa com deficiência sempre foi questionada e inaceitável por décadas e foram vítimas de massacres, barbarismo da sociedade civil, discriminação, abandono cruel e morte, quando compreendida como doença e não como diferença, mais uma característica dentre tantas que distinguem um sujeito do outro, que lhe confere singularidade.

Esse público, em muitas situações, foi compreendido como tendo doenças contagiosas que deveriam ser imediatamente eliminadas, consideradas pessoas subumanas e condenadas à morte por causa de sua aparência e deficiência. $\mathrm{Na}$ época, a sociedade tinha uma mentalidade distorcida da realidade, que se concentrava na "perfeição da pessoa humana" e não na capacidade de regeneração e no desenvolvimento da pessoa com deficiência, temendo que tal deficiência contaminasse a população em geral, a diferença era vista como um "ser humano não normal" (PESSOTTI, 1984, p. 5). Essas iniciativas não estavam integradas às políticas públicas de educação e foi preciso o passar de um século, aproximadamente, para que a educação especial passasse a ser um dos componentes de nosso sistema educacional. De fato, no início dos anos 60 é que essa modalidade de ensino foi instituída oficialmente, com a denominação de "educação dos excepcionais". Pode-se afirmar que a história de pessoas com deficiência no Brasil, está dividida entre três grandes períodos: de 1854 a 1956- marcado por iniciativas de caráter privado; de 1957 a 1993 - definido por ações oficiais de âmbito nacional; de 1993...- caracterizado pelos movimentos em favor da inclusão escolar (MANTOAN, 2001). 
De acordo com Pessotti (1984, p. 6) "Muitos chegam a admitir que o deficiente é possuído pelo demônio, o que torna aconselhável o exorcismo com flagelação para expulsálo”. A história da Educação Especial no Brasil data do início da segunda metade do século XIX e começou com a educação dessas pessoas em escolas ligadas a hospitais psiquiátricos, asilos e também em instituições especializadas. O primeiro período de ensino, no Brasil, foi caracterizado pela segregação. Nos anos 1960, havia um grande número de instituições especializadas e a prática de educação separada em instituições começou a ser questionada porque as pessoas com necessidades educacionais eram isoladas de suas famílias e da vida social. Os ideais liberais divulgados no Brasil, no final do século XVIII e início do século XIX, influenciaram o surgimento da educação das crianças com deficiência, que se deu incialmente, em instituições (JANNUZZI, 2004).

Para Jannuzzi (2004, p. 38) a Educação Especial, desde seu surgimento no final do século XVIII, atende a dois interesses contraditórios: o de oferecer escolaridade a crianças "anormais", ao mesmo tempo em que serve de instrumento básico para a segregação do sujeito "deficiente". Em 1970, as escolas regulares começaram a aceitar matrículas de alunos com deficiência em classes comuns e classes especiais de escolas regulares, tendo início à conquista pelo espaço e pelo direito da escolarização para as pessoas portadoras de necessidades educacionais especiais.

Ao analisar a história da humanidade, percebe-se os diferentes, ninguém é igual a ninguém, a diferença faz parte de nossas culturas, etnicidade, gênero, religiões. Souza Santos (1999, p 62) aponta que precisamos lutar pelo reconhecimento à diferença, entendida como parte constitutiva da singularidade humana, sem abdicar da igualdade de direitos, igualdade de tratamentos e igualdade de condições, porque "temos o direito a ser iguais quando a diferença nos inferioriza, temos o direito a ser diferentes sempre que a igualdade nos descaracteriza". Observa-se que a diferença incomoda e causa desconforto aos que estão contaminados pelo idealismo histórico e utópico do corpo esteticamente adequado, a miopia social que é influenciada pela mídia que imprime na sociedade o processo de exclusão social

Emmel (2002) ressalta que o ideal antigamente era a do adulto saudável e forte. "Essa preocupação era sobre ação militar, defesa da pátria, sucesso nos jogos, boa prática científica (matemática, astrologia, entre outros.), a representação estética da beleza e manutenção da Saúde". Em Esparta, houve a eliminação dos filhos, mais antes disso, passaram por uma inspeção do Estado, para confirmar se eram fortes e saudáveis, então os imaturos, os fracos e os defeituosos foram intencionalmente eliminados. Esse autor menciona também o registro de 
que os romanos descartaram crianças deformadas e não desejadas, em esgotos encontrados, no lado externo do Templo da Misericórdia. Em Atenas também havia o costume de manter vivas apenas as crianças fortes e com boa saúde, mas essa decisão foi tomada pelos pais e não pelo Estado, como em Esparta.

As histórias provam como o ato de abandonar crianças em montanhas e florestas ou jogá-las em penhascos ou em rios era comum na antiguidade, pois eram consideradas pela sociedade como uma ameaça à manutenção social, vistas como subumanas e não como

Desse modo, para analisar a evolução do processo da inclusão das pessoas com deficiência e conhecer as diferentes formas que a sociedade as em percebido em cada época, supõe-se que o entendimento de deficiência é social e historicamente construída, isso significa que em cada momento histórico ela foi vista de uma maneira dependendo da cultura e do processo de informações, crenças, entendimentos e convicções, consequentemente de certa forma foram condenadas a segregação e a invisibilidade. Uma parte da sociedade que exclui parte de seus membros é uma sociedade empobrecida. As ações que melhoram as condições para as pessoas com deficiência resultarão em se projetar em um mundo flexível para todos. $\mathrm{O}^{3}$ que for feito hoje em nome da questão da deficiência terá significados para todos no mundo de amanhã (Declaração de Madri 2003).

Gugel (2006, p. 27) cita que em 1980, a organização Mundial de Saúde (OMS) publicou a Classificação Internacional de Impedimentos, Deficiências e Incapacidades, indicando que as três possibilidades existem em cada pessoas com deficiência porém "essas restrições não lhe retiram o valor, o poder de tomar decisões, de assumir o controle de sua vida e de ter responsabilidades. Aranha (2008. p 15) complementa essa reflexão destacando que

A experiência foi mostrando ter sido um equívoco supor que alguém pudesse se "habilitar para a integração social através de uma vivência segregada, em ambiente não representativo da vida na sociedade mais ampla e na convivência quase que exclusiva com outras pessoas com deficiência.

O surgimento em 1990 do movimento em prol da sociedade inclusiva, iniciado nas Nações Unidas, mediante resolução desse organismo em defesa de uma sociedade para todos, configurou a normativa universal que fundamenta a implantação da inclusão, Conferência Mundial de Educação para Todos, Jomtien (1990). Essa abrangência foi definida em 1994, no

${ }^{3}$ Encontramos a Declaração de Madri em anexo no livro Gugel (2006, p. 195) mais de 600 participantes no Congresso Europeu sobre deficiência que reuniram-se para saudar a proclamação de 2003 como ano Europeu das pessoas com Deficiência. 
conhecido Encontro de Salamanca (Espanha), resultando no documento que marcou época: a Declaração de Salamanca (UNESCO, 1994).

A Declaração de Salamanca veio reafirmar o direito à educação de todos os indivíduos, tal como está inscrito na Declaração Universal dos Direitos do Homem (UNESCO, 1948), e relembrando as diversas declarações das Nações Unidas que culminaram, em 1993, nas Normas das Nações Unidas sobre a Igualdade de Oportunidades para as Pessoas com Deficiência, as quais exortam os Estados a assegurar que a educação das pessoas com deficiência faça parte integrante do sistema educativo (ONU, 1993)

De acordo com a Declaração de Salamanca (1994, p. 43), o princípio fundamental de uma escola inclusiva, em que todos devem aprender juntos, responsabiliza a escola a "[...] reconhecer e responder as necessidades diversas de seus alunos acomodando ambos estilos e ritmos de aprendizagem e assegurando uma educação de qualidade a todos através de um currículo apropriado".

Para Omote (2008), a educação inclusiva não implica em nenhuma ideia nova em especial, pois a educação inclusiva não teve início na década passada com a Declaração de Salamanca (1994). Na verdade, as sociedades humanas vêm-se tornando progressivamente inclusivas, há séculos. O resultado disso é universalização dos direitos do cidadão, com inúmeras conquistas por partes das minorias, em diferentes partes do mundo.

Com vistas à garantia desse princípio, dentre outros aqui não tematizados, a educação inclusiva, no BRASIL, tem como objetivo incluir as crianças no ensino regular, possibilitando tanto a convivência com seus pares, quanto o acesso, permanência e participação nos processos de ensino e aprendizagem. Em seu artigo $5^{\circ}$, a Constituição Federal (BRASIL, 1988), garante a todos o direito à igualdade, afirmando a todos os brasileiros o direito a serem protegidos e respeitados com base em uma Declaração Universal dos Direitos Humanos (1948) Os direitos negados causam prejuízos irreparáveis à dignidade da ética de muitos outros direitos.

O Artigo $8^{\circ}$, da Lei 7 853/89,que Dispõe sobre o apoio às pessoas portadoras de deficiência, sua integração social, sobre a Coordenadoria Nacional para Integração da Pessoa Portadora de Deficiência, institui a tutela jurisdicional de interesses coletivos ou difusos dessas pessoas, disciplina a atuação do Ministério Público, define crimes, (BRASIL, 1989), afirma que a recusa em matricular um aluno em uma escola, seja pública ou privada, por razões relacionadas a qualquer deficiência é crime. Além de serem multados, diretores ou funcionários das escolas que se recusarem a matricular pessoas com deficiências podem ser 
condenados de um a quatro anos de prisão. A ninguém é negado o direito de aprender e desenvolver suas habilidades. Os direitos humanos são dirigidos a todos, independentemente da classe social, gênero, etnia, religião, características individuais, dentre outras.

O artigo 205, da Constituição Federal (BRASIL, 1988), trata do direito de todos à educação, ao apontar o desenvolvimento integral da pessoa, sua preparação para o exercício da cidadania e sua qualificação para o trabalho, enquanto o artigo 206, inciso I, estabelece os seguintes princípios para o ensino: "igualdade de condições, acesso e permanência na escola".

Essas normativas dispostas na Constituição Federal (BRASIL, 1988), dentre outras, foram, posteriormente, asseguradas no Estatuto da Criança e do Adolescente (ECA) (BRASIL, 1990), na Lei n ${ }^{\circ}$ 9.394, que estabelece as diretrizes e bases da educação nacional (BRASIL, 1996).

Do ponto de vista das políticas educacionais, a Política Nacional de Educação Especial (BRASIL, 2008), que reorganizou o sistema educacional brasileiro na perspectiva da educação inclusiva, conferindo à Educação Especial o caráter de suporte ao processo de escolarização dos alunos que compõem seu público-alvo, foi subsidiada pelas conquistas legais asseguradas, por exemplo, nas Diretrizes Nacionais para a Educação Especial no Ensino Fundamental (BRASIL, 2001), bem como nas estratégias e conteúdos do currículo de Educação Infantil (BRASIL,1998).

A partir da Política Nacional de Educação Especial na Perspectiva da Educação Inclusiva (BRASIL, 2008), uma importante conquista foi assegurada: o suporte da Educação Especial ao seu público-alvo desde a Educação Infantil ao ensino superior. Entretanto, desde então, a operacionalização das normativas e ações previstas a tal público no contexto da Educação Infantil ainda carece de investimentos, quer seja em tal operacionalização, quer seja na reorganização escolar para a adoção de práticas pedagógicas coerentes com a perspectiva inclusiva.

Quanto à Educação Infantil afirma que:

Nas últimas décadas, vem se consolidando, na Educação Infantil, a concepção que vincula educar e cuidar, entendendo o cuidado como algo indissociável do processo educativo. Nesse contexto, as creches e préescolas, ao acolher as vivências e os conhecimentos construídos pelas crianças no ambiente da família e no contexto de sua comunidade, e articulálos em suas propostas pedagógicas, têm o objetivo de ampliar o universo de experiências, conhecimentos e habilidades dessas crianças, diversificando e consolidando novas aprendizagens, atuando de maneira complementar à educação familiar - especialmente quando se trata da educação dos bebês e das crianças bem pequenas, que envolve aprendizagens muito próximas aos 
dois contextos (familiar e escolar), como a socialização, a autonomia e a comunicação (BRASIL, 2016, p. 34).

Para Peter Mittler, (2003) a inclusão é uma visão, uma estrada a ser viajada, mas uma estrada sem fim, com todos os tipos de barreiras e obstáculos, alguns dos quais estão em nossas mentes e em nossos corações. A família deve ser orientada e motivada a colaborar e participar do programa educacional, promovendo desta forma uma interação com a criança portadora de necessidades especiais. Também é fundamental que a família incentive a prática de tudo que a criança assimila. Segundo Mantoan (2006), as pessoas não podem ter um lugar no mundo sem considerar o outro, valorizando o que ele é, e o que ele pode ser, sendo que para os professores, o maior ganho está em garantir a todos o direito à educação a educação inclusiva.

\section{O que esperar da nova Base Nacional Comum Curricular - BNCC - para a Educação Infantil e a inclusão do aluno com deficiência?}

Mais recentemente, surge a BNCC com a proposta de reverter a situação de exclusão histórica e marginalizadora com os alunos com deficiência, reconhecendo a necessidade de práticas pedagógicas inclusivas e de diferenciação curricular, conforme estabelecido na Lei Brasileira de Inclusão da Pessoa com Deficiência (Lei $n^{\circ}$ 13.146/2015), Lei Brasileira de Inclusão da Pessoa com Deficiência (Estatuto da Pessoa com Deficiência), destinada a assegurar e a promover, em condições de igualdade, o exercício dos direitos e das liberdades fundamentais por pessoa com deficiência, visando à sua inclusão social e cidadania.

O que pode-se destacar O que pode-se destacar é que a BNCC deixa claro que precisa haver um trabalho com uma intencionalidade, além disso, diferente dos outros documentos ela apresenta quadros demonstrando o que se espera da criança em cada etapa, o que é algo novo, e que precisa ser mais discutido pois demonstra um interesse no desenvolvimento da criança. Percebe-se na BNCC que a Educação Infantil novamente tem um grande vínculo com a questão do cuidar, o que é comum aos demais documentos, em relação ao cuidado com o corpo, alimentação, higiene, é importante, mas acredita-se que uma Educação Infantil deve ir além do educar para a autonomia, e visar o desenvolvimento infantil como um todo. Deparase com discursos que, em sua maioria, comungam com os ideais construtivistas, trazendo em muitos momentos a criança como protagonista do processo educativo, o que pode ser discutido em relação a brincadeira, que em várias situações é vista como algo natural e espontânea a criança. 
Segundo o MEC (2017, p. 7) “[...] a BNCC soma-se aos propósitos que direcionam a educação brasileira para a formação humana integral e para a construção de uma sociedade justa, democrática e inclusiva”.

Nos anos iniciais, pretende-se que, em continuidade às abordagens na Educação Infantil, as crianças ampliem os seus conhecimentos e apreço pelo seu corpo, identifiquem os cuidados necessários para a manutenção da saúde e integridade do organismo e desenvolvam atitudes de respeito e acolhimento pelas diferenças individuais, tanto no que diz respeito à diversidade étnico-cultural quanto em relação à inclusão de alunos da educação especial.

Essas decisões precisam, igualmente, ser consideradas na organização de currículos e propostas adequados às diferentes modalidades de ensino (Educação Especial, Educação de Jovens e Adultos, Educação do Campo, Educação Escolar Indígena, Educação Escolar Quilombola, Educação a Distância), atendendo-se às orientações das Diretrizes Curriculares Nacionais.Com a inclusão da Educação Infantil na BNCC, mais um importante passo é dado nesse processo histórico de sua integração ao conjunto da Educação Básica.

Em 2017, a aprovação da Base Nacional Comum Curricular (BNCC) instaurou a discussão em torno do papel do Estado na elaboração, implementação e regulação de uma proposta curricular nacional para a educação básica, suscitando posicionamentos favoráveis e contrários a centralização curricular via Ministério da Educação (MEC).

A mudança da Base Nacional Comum Curricular desenha os objetivos de aprendizagem para a Educação Infantil (crianças de 0 a 5 anos), aprovada a partir de 2018 (BRASIL, 2018), denotam tempos de grandes desafios. Espera-se que, com ela, seja possível padronizar a educação no país no âmbito do currículo escolar. Nessa nova base espera-se maior envolvimento da família e da sociedade. Estudos revelam que a participação da família no ambiente escolar de seus filhos é baixa e pouco representativa no sentido de participação da proposta pedagógica da escola, no acompanhamento escolar e nos projetos escolares de visar a educação inclusiva.

A Pesquisa Atitudes pela Educação (TODOS PELA EDUCAÇÃO, 2014) divulgada pelo movimento Todos pela Educação, mostra que apenas 12\% dos pais sãos comprometidos, ou seja, acompanham o desempenho dos filhos na escola, comparecem às atividades escolares e têm relação próxima com crianças e jovens. A pesquisa envolveu 2.002 pais ou responsáveis de alunos de 4 a 17 anos, matriculados da Educação Infantil ao ensino médio, em escolas públicas e particulares de todas as regiões do país, isso demonstra que ainda existe muito 
trabalho a fazer para criar uma integração entre os diversos setores da sociedade, de forma a gerar engajamento e interesse pela criança de com necessidades especiais.

O que não consta na nova BNCC, para Educação Infantil e inclusão, apesar das alterações, é que ela não faz menções ainda das "questões de gênero", pois o Conselho Nacional de Educação prefere tratar do assunto de forma separada. Em relação ao ensino religioso, que é um outro ponto de debates, sua inserção pretende fazer com que os alunos possam conhecer os aspectos estruturantes das diferentes tradições e movimentos religiosos. As mudanças na Educação Infantil para 2018 têm potencial de ajudar na redução da desigualdade do ensino. No entanto, dependerão também da qualidade da implementação por parte dos municípios.

O conteúdo esclarece o que são seis os direitos de aprendizagem, uma novidade da BNCC, o que explica os cinco campos de experiência que vão reformular a organização curricular.

As diferenças entre os três documentos estruturantes da etapa: Referencial Curricular Nacional para a Educação Infantil (RCNEI), de 1998, estabelece o que deve ser ensinado Diretrizes Curriculares Nacionais para a Educação Infantil (DCNEI), de 2009 coloca a criança no centro e se aprofunda em como garantir o que ela tem direito de aprender e a BNCC (2017) reforça a concepção de criança como protagonista e institui os cinco Campos de Experiências e objetivos de aprendizagem baseados nos Direitos de Aprendizagem.

As Diretrizes Curriculares Nacionais para a Educação Infantil (DCNEI), de 2009, já mostram um avanço na direção de colocar a criança em foco, mas ainda não aparece a educação inclusiva de forma clara e propositiva que serviram como um uma fundamentação teórica para a Base. Nas DCNEI, a atenção já estava voltada para a criança e o documento reforça a importância de o aluno ter acesso a inclusão ao conhecimento cultural e científico, assim como o contato com a natureza, preservando o modo que a criança se situa no mundo. As DCNEI colocam o foco nas interações e na brincadeira como eixos estruturantes do currículo, além de considerar os princípios éticos, políticos e estéticos que deveriam nortear a produção do conhecimento nas escolas infantis.

Outro ponto a ser observado é o marco conceitual da relação entre o cuidar e o educar das DCNEI, algo que a Base valida e reforça. A BNCC, na Concepção da criança, reforça a visão da criança como protagonista em todos os contextos de que faz parte: ela não apenas interage, mas cria e modifica a cultura e a sociedade. Objetivo a partir de um significativo avanço no entendimento de como a criança aprende, oferecer referências para a construção de 
um currículo, baseadas em direitos de desenvolvimento e aprendizagem bem definidos. Como está organizado, as diversas áreas de conhecimento e as diferentes linguagens são integradas por meio dos Campos de Experiência. Parte-se do pressuposto de que a criança aprende por meio das experiências vividas no contexto escolar.

Os campos de experiência buscam integrar as diferentes linguagens e as diversas áreas do conhecimento presentes na Educação Infantil. Embora os conceitos de eixo (RCNEI), linguagens (DCNEI) e campos de experiências (BNCC) não sejam excludentes, pois eles se aproximam em vários aspectos, consideramos que este último conceito apresenta avanços no modo de organização do trabalho pedagógico na Educação Infantil. Apesar de o RCNEI e das DCNEIs se preocuparem com a não fragmentação do conhecimento, com a não disciplinarização da Educação Infantil e com a necessidade de integração e articulação do trabalho pedagógico com a educação inclusiva entre as diferentes áreas e sujeitos, a ideia de campos de experiências, que está em consonância com a concepção de infância subjacente à BNCC, atribui centralidade à criança na construção do conhecimento.

Ao valorizar as experiências infantis inclusivas, o modo como elas negociam e interagem em grupo, o foco do processo de ensino-aprendizagem se desloca do que se "passa para as crianças", para o que se "passa com e entre elas", ou seja, com os sentidos que constroem na sua relação com os objetos do saber, com os seus pares e com os adultos.

Na BNCC, os processos pedagógicos na Educação Infantil partem da concepção de que a construção de conhecimento pelas crianças se efetiva por meio da participação direta delas nas diferentes práticas cotidianas. Nesse processo, o respeito ao modo como as crianças pequenas se relacionam com o mundo e a sua especificidade, deficiências e dos recursos que utilizam - como a corporeidade, a linguagem e a emoção - são reconhecidos como essenciais nos processos de aprendizagem.

Os direitos de aprendizagem todas as crianças e das com deficiência respeitando o desenvolvimento desse campo de experiência, expressos pelos verbos conviver, brincar, explorar, participar, comunicar e conhecer-se, sinalizam a categoria corpo e movimento como forma de expressão, de produção de sentidos e de experiências por parte das crianças. Assim sendo, esses direitos valorizam as crianças como produtoras de cultura, de conhecimentos e ratificam o entendimento de que essa categoria é fundamental na interação entre elas, fortalecendo a sua cultura de pares. Com efeito, a visibilidade a inclusão e importância atribuída ao corpo e ao movimento na Educação Infantil estão relacionadas com as 
oportunidades que as crianças têm de produzir culturas, como autoras de suas próprias práticas e não de forma estabelece explicita a educação inclusiva na Educação Infantil.

Embora a descrição dos direitos de aprendizagem e desenvolvimento referentes ao campo de experiência “corpo, gestos e movimentos" traga avanços significativos em relação aos documentos anteriores, percebemos, em alguns objetivos de aprendizagem destinados aos diferentes subgrupos etários (bebês, crianças bem pequenas e crianças pequenas), uma apropriação utilitarista do corpo e do movimento, em que o sujeito parece estar "fora" do seu próprio corpo, por exemplo: "Demonstrar controle e adequação do uso de seu corpo na participação em momentos de cuidado, brincadeiras e jogos [...]" e "Fazer uso de movimentos cada vez mais precisos [...]” (BRASIL, 2016, p. 72).

Apesar de toda bagagem de estereótipos, as crianças pequenas ainda encontram espaços para a transgressão, para a superação e para expressão dos seus desejos. Assim, as crianças pequenas, com seus corpos e com suas espontaneidades, problematizam e questionam esses modelos centrados no adulto.

A BNCC extrapola a função de apresentar os pressupostos gerais para a Educação Infantil e Inclusiva e entra em questões curriculares específicas, que, em nossa compreensão, deveriam ser desenvolvidas por cada unidade de ensino, considerando as particularidades sua educação inclusiva e as singularidades dos sujeitos presentes em cada contexto.

As competências gerais da Educação Básica propostas pela BNCC, seis direitos de aprendizagem e desenvolvimento asseguram, na Educação Infantil, as condições para que as crianças aprendam em situações nas quais possam desempenhar um papel ativo em ambientes que as convidem a vivenciar desafios e a sentirem-se provocadas a resolvê-los, nos quais possam construir significados sobre si, os outros e o mundo social e natural.

\section{Considerações finais}

Diante dos apontamentos levantados no decorrer desta pesquisa, resta-nos a afirmar que muitas certezas foram abaladas, de que concepções naturalizadas precisam ser desconstruídas, valores revistos e colocados sob o prisma do repensar/problematizar questões de inclusão, Educação Infantil, currículo. Este caminhar científico, possibilitou-nos o entendimento de que estamos avançando no caminho da inclusão madura, ampliada e possível de intervenção no espaço escolar sobre as questões em torno dos temas diversidade humana. 
Como também a percepção de que a inclusão da pessoa com deficiência, relegada, negada e inivisibilizada por quem deveria torná-la uma questão de debate na sociedade.

A utilização da frase "Um dia me disseram que as nuvens não eram de algodão", no início do artigo tem uma razão na vida temos sempre um/uma alguém que nos ensina a ver o mundo, a caminhar em direção a inclusão escolar como um conceito funcional, a superar o preconceito, a viver e sobreviver com liberdade. A expectativa é que esta reflexão sirva para orientar os que precisam enxergar aquele por direito já resguardado tem garantia de sua matricula, inserir-se na escola é o desafio para sair da situação de desamparado, incapaz, invisível e que todos somos diferentes e vivemos a diversidade humana.

A imposição de um lugar vazio, da invisibilidade, da indiferença social, decorrentes de uma marginalização histórica, das pessoas com deficiência, evidenciou-se, no transcorrer do trajeto que se constituiu na presente reflexão, e esta uma consideração fundamental no interior da proposição desse trabalho e se coloca como uma constatação importante para se iniciar a reflexão.

Nesse sentido, a BNCC assume o caráter de responder às demandas internacionais de mercado, ao criar e implementar padrões curriculares e educacionais que servirão de guias para os professores e de referência para os programas de formação de professores e avaliações escolares e institucionais. Há um grande distanciamento entre planejamento, currículo e avaliação que contempla as especificidades das pessoas com deficiência e a proposta curricular defendida pela BNCC visando a Educação Infantil.

As lacunas e os equívocos existentes reforçam a ideia de que Educação Especial é um apêndice da Educação Básica. Assentada numa ideologia de Educação Inclusiva que promete garantir a inclusão social para estudantes com deficiências, TGD e altas habilidades/superdotação. O discurso de uma Educação Especial Inclusiva revela uma fantasia de Inclusão Escolar que, uma vez mais, viabiliza-se por meio de sucessivas exclusões.

Além disso, a crítica construída por Omote (2003) aponta para uma das possíveis causas do sentimento de despreparo dos professores do ensino regular. O autor afirma que falta conexão entre os pesquisadores da educação especial e os professores do ensino regular. Segundo ele todos os profissionais e cidadãos necessitam ser formados na perspectiva da inclusão e não apenas os educadores. "Não se pode admitir que a inclusão seja preocupação apenas dos estudiosos e profissionais da área de educação especial” (OMOTE, 2003, p. 154155). Esta crítica nos faz refletir e questionar o quanto os professores do ensino regular estão incluídos no contexto da educação inclusiva, ou se persiste a separação entre estes e os 
pesquisadores da educação inclusiva. Não há possibilidade de avançar na inclusão escolar se não houver uma maior disseminação das teorias da educação inclusiva.

Apesar disso, considera-se que esta reflexão pode ser ampliada em outra ocasião, por exemplo em uma pesquisa com participação de professores, a fim de possibilitar que se compreenda a percepção do professor em relação às políticas públicas da inclusão escolar e outros aspectos que extrapolam a sua atuação e caminhos para encontrar o "lugar" da inclusão nos diferentes contextos educacionais.

\section{REFERÊNCIAS}

ARANHA, M. S. F. Educação inclusiva: a fundamentação filosófica. Brasília: Ministério da Educação, Secretaria de Educação Especial, 2004.

BRASIL. Constituição da República Federativa do Brasil: promulgada em 5 de outubro de 1988. Organização do texto: Juarez de Oliveira. 4. ed. São Paulo: Saraiva, 1990. 168 p. (Série Legislação Brasileira).

BRASIL. Referencial Curricular Nacional para a Educação Infantil. Brasília: MEC/SEF, 1998.

BRASIL. Ministério da Educação. Conselho Nacional de Educação. Diretrizes Curriculares Nacionais para a Educação Infantil. Brasília/DF, 2009.

BRASIL. Secretaria de Educação Básica. Revisão das Diretrizes Curriculares Nacionais para a Educação Infantil. In: BRASIL. Diretrizes Curriculares Nacionais Gerais da Educação Básica. Brasília: MEC, SEB, DICEI, p. 80-101, 2013.

BRASIL. Base Nacional Comum Curricular. Versão preliminar. Brasília: MEC, 2015. Disponível em: http://basenacionalcomum.mec.gov.br/\#/site/inicio. Acesso em: 10 mar. 2018.

CARNEIRO, R. U. C. Dossiê: Trabalho docente no contexto da inclusão escolar. Revista Ibero-Americana de Estudos em Educação, [S.1.], v.11, n. esp. 2, p. 856-860, set. 2016. ISSN 1982-5587.

CARVALHO, R. S. Problematizando discursos generificados em livros de formação de professores de Educação Infantil. Rev. Eletrônica Pesquiseduca, Santos, v. 06, n. 11, p. 725, jan./jun. 2014.

DECLARAÇÃO DE SALAMANCA. Brasília, 1994. Disponível em: http://portal.mec.gov.br/seesp/arquivos/pdf/salamanca/pdf.pdf. Acesso em: 27 dez 2018.

EMMEL, M. L. G. Deficiência Mental In: Palhares, M. S. Marins, S. C. F (Org.) Escola Inclusiva. São Carlos: Ed. Da UFSCar, 2002. 
JANUZZI, G. M. A educação do deficiente no Brasil: dos primórdios ao início do século XXI. Campinas: Autores Associados, 2004.

KISHIMOTO, T. M. Jogo, brinquedo e brincadeira. São Paulo: Cortez, 2008.

MACEDO, E. Base Nacional Curricular Comum: novas formas de sociabilidade produzindo sentidos para a educação. Revista e-Curriculum, São Paulo, v. 12, n. 03, p. 1530-1555, out./dez. 2014.

MANTOAN, M. T. E. Inclusão Escolar: O que é? Por quê? Como fazer? Editora moderna 2006.

MITTLER, P. Educação Inclusiva: Contextos Sociais. São Paulo: Artmed, 2003.

OMOTE, S. Diversidade, educação e sociedade inclusiva. In: OLIVEIRA, A. A. S.; OMOTE, S.; GIROTTO, C. R. M. (Org.). Inclusão escolar: as contribuições da educação especial. São Paulo: Fundep, 2008.

PESSOTTI, I. Deficiência Mental: da superstição à ciência. São Paulo: T. A. Queiroz, 1984.

SASSAKI, R. K. Construindo uma sociedade inclusiva. Rio de Janeiro: Ed W.V.A, 2007.

VIGOTSKI, L. S. Obras Completas V. Fundamentos de defectologia. Habana: Editorial Pueblo y Educación, 1997.

\section{Como referenciar este artigo}

Solange Aparecida de Souza MONTEIRO.; Paulo Rennes Marçal RIBEIRO. O lugar das crianças com deficiências na educação infantil e políticas de inclusão na educação brasileira. Revista Ibero-Americana de Estudos em Educação, Araraquara, v. 14, n. esp. 1, p. 730745, abr., 2019. E-ISSN: 1982-5587. DOI: 10.21723/riaee.v14iesp.1.12203

Submetido em: 28/06/2018

Revisões requeridas: 30/08/2018

Aprovado em: 20/11/2018 